CASE REPORT

\title{
Lifesaving Device Presenting as Bronchial Foreign Body
}

\author{
Sunil Kumar ${ }^{1}$, Hitendra P Singh ${ }^{2}$, Anupriya Hajela ${ }^{3}$
}

\begin{abstract}
The common tracheobronchial foreign bodies in adults are food items such as peanuts. Aspirated medical devices are rarely seen. If a tracheobronchial foreign body is not diagnosed and removed early, severe complications such as pneumonia and atelectasis can result. We are presenting a 50-year-male patient with accidental aspiration of fractured metallic tracheostomy tube in the left main bronchus. Patient was otherwise asymptomatic. The foreign body was removed under general anesthesia using a zero degree endoscope and bronchoscopic forceps. Postoperative period was uneventful, and the patient was discharged the next day with oral medications. This case has been described here as lifesaving device presented as life-threatening emergency and to highlight the importance of tracheostomy tube care.
\end{abstract}

Keywords: Lifesaving device, Tracheobronchial foreign body, Tracheostomy tube.

Otorhinolaryngology Clinics: An International Journal (2019): 10.5005/jp-journals-10003-1315

\section{BACKGROUND}

A tracheobronchial foreign body (FB) in adults is usually seen in patients with decreased consciousness level due to alcohol intoxication, sedation from a drug, medical procedures, or neurological deficit. ${ }^{1}$ Tracheostomy is one of the most important emergency procedures in airway management. It is commonly performed in elective as well as emergency situations. A significant number of patients need permanent tracheostomies that require long-term care and management. There are various types of tracheostomy tubes, metallic as well as nonmetallic. Metallic tubes were being used in past days. Improper tracheostomy care can result in adverse outcomes such as fracture of tracheostomy tubes with subsequent aspiration of the fragment into the airway. Airway foreign bodies and failure of airway devices require urgent intervention due to the inherent risk of airway compromise. Thus, it is needed to understand the factors contributing to such type of complications, in order to prevent its occurrence, recognize, and manage accordingly.

\section{Case Description}

A 50-year-male patient presented to the outpatient department with history of aspiration of fractured tracheostomy tube while attempting to remove it for cleaning. The patient was tracheostomized 23 years ago after laryngotracheal trauma following road traffic accident. That resulted in bilateral fixed vocal cords. At that time metallic tracheostomy tube was placed. After proper instruction about tracheostomy tube care patient was discharged from the hospital. Since last 23 years patient was regularly taking care of his tracheostomy tube properly. Patient was able to remove and clean the tracheostomy tube himself. Patient did not seek any opinion with specialist for last 2 years regarding tracheostomy tube or its care. Patient was hemodynamically stable and there was no significant respiratory distress at the time on presentation. Chest examination revealed slightly decreased in breath sounds on left side. A chest X-ray showed that a radio-opaque foreign body was lodged in the left main bronchus (Figs 1 and 2). The patient was planned for the removal of foreign body under sedation in anesthetic guidance. ${ }^{1-3}$ Department of Otorhinolaryngology and Head-Neck Surgery, King
George's Medical University, Lucknow, Uttar Pradesh, India

Corresponding Author: Sunil Kumar, Department of ENT and HeadNeck Surgery, King George's Medical University, Lucknow, Uttar Pradesh, India, Phone: +91 9415820661, e-mail: drsunil_kumar123@ rediffmail.com

How to cite this article: Kumar S, Singh HP, Hajela A. Lifesaving Device Presenting as Bronchial Foreign Body. Int J Otorhinolaryngol Clin 2019;11(2):52-54.

Source of support: Nil

Conflict of interest: None

Foreign body was visualized using $0^{\circ}$ rigid endoscope through the tracheostomy stoma (Fig. 3). The fractured segment was removed without much difficulty using a $0^{\circ}$ rigid endoscope and foreign body-grasping forceps through the tracheostomy stoma. The tracheostomy tube was fractured close to the neck plate of the tracheostomy (Fig. 4). After removal of foreign body, proper suction was done to clear the secretions. There was significant mucosal trauma during removal of foreign body. The patient was ventilated intermittently via the stoma to maintain the oxygen saturation. Patient was shifted to postoperative room, and the postoperative period was uneventful. An uncuffed nonmetallic tracheostomy tube was placed and patient was discharged after prescribing one-week oral antibiotic and proper instruction about tracheostomy tube care.

\section{Discussion}

Tracheostomy is an emergency and lifesaving procedure. It is done in the emergency as well as elective situations. In past days, metallic tracheostomy tubes were frequently used with various complications related to it. Fracture and aspiration of tube are rarely seen nowadays due to increased use of nonmetallic tubes. Aspirated fractured tracheostomy tube was first reported by Bassoe and Boe. ${ }^{2}$ Fracture and aspiration of tracheostomy tubes are seen in tubes made of silver, sterling silver, stainless steel, PVC, and silicone. ${ }^{3}$ Tube-flange junction followed by neck-tube

() The Author(s). 2019 Open Access This article is distributed under the terms of the Creative Commons Attribution 4.0 International License (https://creativecommons. org/licenses/by-nc/4.0/), which permits unrestricted use, distribution, and non-commercial reproduction in any medium, provided you give appropriate credit to the original author(s) and the source, provide a link to the Creative Commons license, and indicate if changes were made. The Creative Commons Public Domain Dedication waiver (http://creativecommons.org/publicdomain/zero/1.0/) applies to the data made available in this article, unless otherwise stated. 


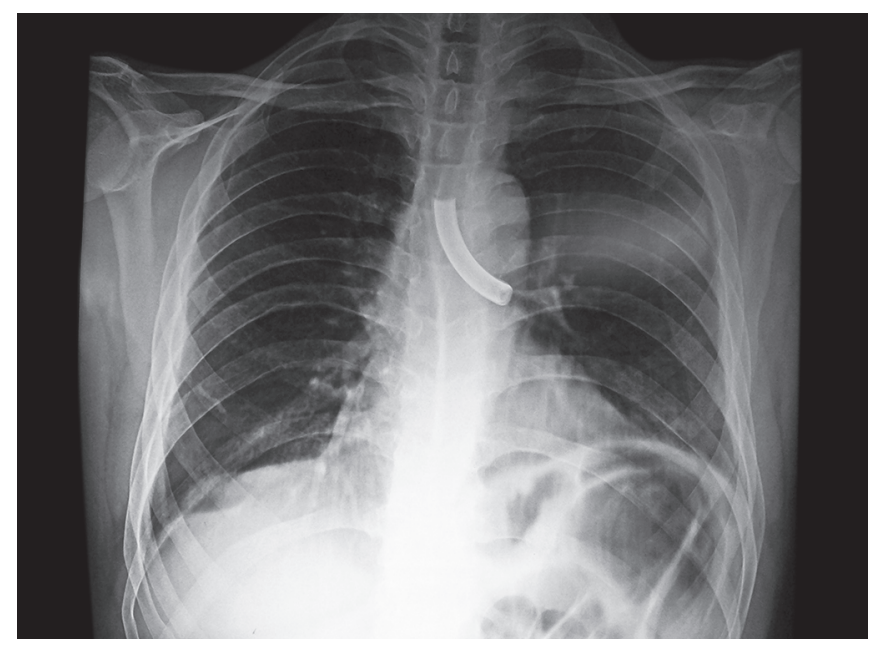

Fig. 1: X-ray AP view showing metallic foreign body in left bronchus

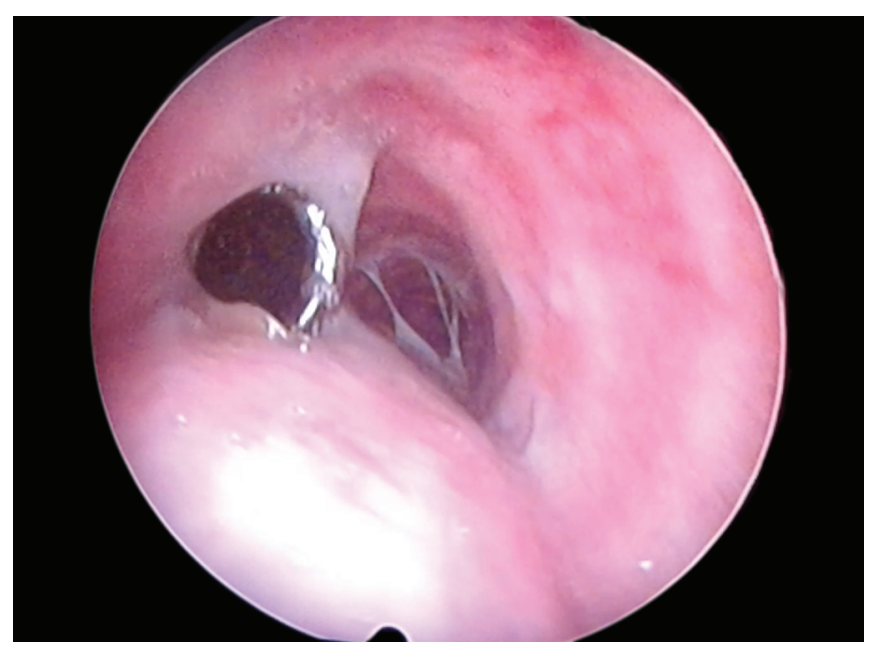

Fig. 3: Endoscopic view showing foreign body in left bronchus

junction and at fenestration site is the most common site for fracture because of higher mechanical stress due to repeated use and out-and-down movements. There are various factors that contribute to weakening and subsequent fracture of the tubes. Repeated cleaning with bleaching solutions and boiling causes weakening of the tube material, leading to fracture. ${ }^{4}$ In case of stenosis, the force required to remove and replace the tube is higher, which further increases the risk of fracture. Alkaline bronchial secretions also play an important role in the weakening of metallic tubes especially for those made with alloys of copper. ${ }^{5,6}$ Basic carbonates form by the action of alkaline secretions of tracheobronchial tree, causes greenish deposition and erosion of the metal, described as "season cracking." ${ }^{2}$ Rarely, manufacturing defects lead to fracture within hours to days of insertion of tube. ${ }^{7,8}$ Clearly, prolonged use of a tracheostomy tube is a major factor for failure mostly due to the cost of the tube and restricted access to follow-up. As most of the patients with aspirated tracheostomy tubes self-present with little or no symptoms, it is important to properly examine the tracheostomy tubes on follow-up to identify impending fracture. A very close observation is important especially in children and the critically ill patients who are unable to point out the fracture and aspiration

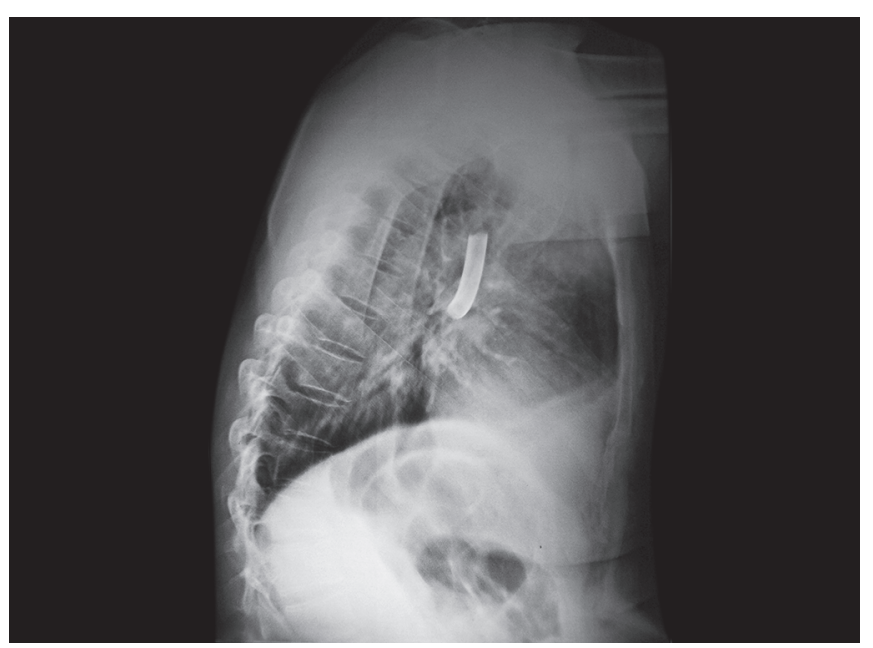

Fig. 2: X-ray lateral view showing metallic foreign body in bronchus

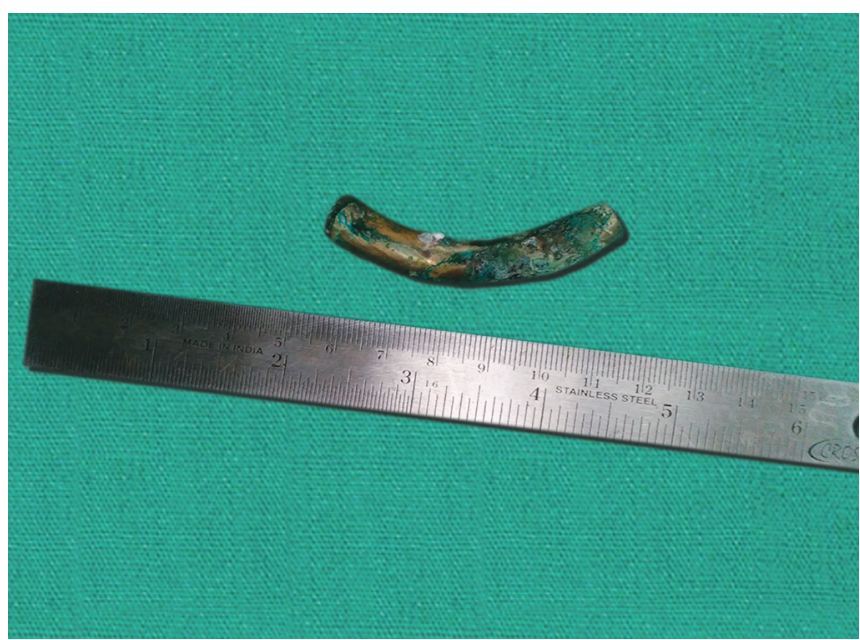

Fig. 4: Metallic foreign body (broken tracheostomy tube) after removal

of the tracheostomy tube. To prevent the tracheostomy tube fracture, it should be replaced with new one and before insertion, each tube should be closely examined for manufacturing defects. Any foreign body in the airway causes a risk of obstruction but in case of tracheostomy tubes, a large lumen enables airflow. Deaths secondary to acute airway obstruction are reported in the pediatric populations, due to the smaller airway caliber. ${ }^{4,8}$ In cases with no significant airway obstruction, foreign body can be retrieved using flexible, rigid bronchoscope, or $0^{\circ}$ endoscope along with the foreign body grasping forceps. A stomal release may be required to allow instrumental access. When removal of the foreign body is difficult, prolonged, and traumatic, high dependency care may be necessary.

\section{References}

1. Limper AH, Prakash BS. Trachobronchial foreign bodies in adults. Ann Intern Med 1990;112:604-609. DOI: 10.7326/0003-4819-112-8-604.

2. Bassoe $\mathrm{HH}$, Boe J. Broken tracheotomy tube. Lancet $1960 ; 275$ : 1006-1007. DOI: 10.1016/s0140-6736(60)90890-4.

3. Takanami I, Abiko T, Kurihara H. Fracture of silicone tracheal T-tube: a rare complication. J Thorac Cardiovasc Surg 2007;134:1362-1363. DOI: $10.1016 / j . j t c v s .2007 .01 .094$. 
4. Brockhurst PJ, Feltoe CK. Corrosion and fracture of a silver tracheostomy tube. J Laryngol Otol 1991;105:48-49. DOI: 10.1017/s0022215100114811.

5. Krishnamurthy A, Vijayalakshmi R. Broken tracheostomy tube: a fractured mandate. J Emerg Trauma Shock 2012;5:97-99. DOI: 10.4103/0974-2700.93098.

6. Shashinder S, Tang IP, Kuljit S, et al. Fracture synthetic tracheostomy tube: an ENT emergency. Med J Malaysia 2008;63:254-255.
7. Wu C-T, Lin J-J, Yeh R. Migration of fragmented tracheostomy tube into left main bronchus. Int J Pediatr Otorhinolaryngol Extra 2007;2: 58-60.

8. Lynrah ZA, Goyal S, Goyal A, et al. Fractured tracheostomy tube as foreign body bronchus: our experience with three cases. Int J Pediatr Otorhinolaryngol 2012;76:1691-1695. DOI: 10.1016/ j.ijporl.2012.07.033. 